\title{
The change of livelihood patterns and dilemma about Ecological \\ Migration in national regions
}

\author{
SUI Yi ${ }^{1}$ \\ Social and psychological college of Southwest Minzu University,Chengdu Sichuan, China \\ suiyi811@163.com
}

Keywords: ecological migration; livelihood patterns; dilemma of livelihood reconstruction

Abstract. The ecological migration has been one of the hot issues discussed in recent years. This paper will, on the basis of systematic examination of the ecological migration's domestic and international theories, research methods and typical cases, make analysis on the change of the ecological migration's livelihood patterns in multi-ethnic regions under different national social and cultural contexts, find the dilemma of the ecological migration's livelihood reconstruction, including the sustainability of the government's plans, changes of ecological resources, loss of public resources, absence of the major component of migrants and so on, and come up with a solution.

\section{Introduction}

The southwest of our country is a minority area where natural environment is complicated, where means of livelihood are diversified, where the social structure is special, and where the cultural patterns are diverse. In recent years, with the rapid deterioration of the ecological environment, the ecological migration has emerged. The serious environmental and social problems are in urgent need of the study of sociology. The focus of this paper will be the analysis on the changes of the ecological migration's livelihood patterns under different national social and cultural contexts and the influence factors, with the application of the "Rational Choice" theory. This paper will also make suggestions on the development and management of the ecological migration.

In consideration of the distribution of the ecological migration and the ethnic diversity in southwest ethnic areas, this paper intends to choose the following representative villages as key research objects (involving the Tibetan, the Qiang, the Yi and other nationalities.

\section{Overseas and Domestic Research Status of the Ecological Migration}

\section{Overseas Research Status}

Overseas researches on the ecological migration are not abundant, but their researches on the aspect of population migration are in large amount. Many subjects, including economics, politics,

\footnotetext{
1. This paper is a partial result of central universities' Basal Research Fund Project: Behavior Selection and its Evolution of Ecological Immigrants-A Case Study of Ecological Immigrant Village in Liangshan Prefecture, Sichuan Province. Ratification NO:82001670
}

Sui Yi (Female, 1985) Social and psychological college of Southwest Minzu University for Nationalities. Research Directions: Environmental Sociology and Immigration Sociology. suiyi811@163.com 
sociology, demography, and so on, have done researches on population shift and migration. After a carding of overseas researches, it's found that the researches on the ecological migration mainly focus on the following aspects: first, discussions of international scholars about the importance of the ecological migration. Richard Leete, scholar of United Nations Fund for Population Development, and Alexandra Winkels and W.NeilAdger from college of environmental sciences of University of East Anglia, all think the necessary ecological migration is the effective action to alleviate these problems. Second, sociology researches on the ecological migration. (Scudder 1991; Scudder 1973). Scudder's analytical framework divides the migration process of the ecological migration into four phases. The first phase is to project, to develop the initial infrastructure and to enlist settlers; the second phase is the transition phase, when migrants move from one residence to another, and the phase will take at least three to five years, or even longer; the third phase is the phase of economic and social development, when migrants' life and production level are gradually recovered and increased and they actively promote the community inclusion; the fourth phase is the delivery and integration phase, when the right of controlling is delivered to settlers and local organizations. Third, researches on the settlement activities of the ecological migration. Scholars, Elmhirst, Rebecca (1999) and Evans Peter (1996) think the process of migrants' moves is a systematic process of reconstruction and rebuilding and that the migrants' livelihood reconstruction programs should be made sustainable, with the application of systematic planning concepts. At the same time, the actual needs of fragile migrants should be paid special attention. Finally, related researches on the settlement objectives of the ecological migration. The World Bank proposed that the standard of migrants' living should be recovered at least as high as their previous ones and they should be provided with the necessity in their production and living, especially the necessary land and facilities.

\section{Current Status of Domestic Ecological Migration Research}

The study on ecological migration mainly focuses on the following aspects: First, the definition of ecological migration. First of all, the literature about the concept of "ecological immigration" is presented by Xu Jiang who works in the Chinese Academy of Sciences and was published the paper "on environmental immigration" in 1996. He was the first one to put forward the issue of environmental immigration in the article systematically. However, Bao Zhiming (2004) argued that ecological migration mainly included two aspects of meaning. Shi Guoqing (2010) defined and differentiated ecological migration, environmental migration, disaster resettlement and project migration, respectively. And he also pointed out that the object of ecological migration is always the poor population. In the meantime, these populations can also be achieved improved production and living conditions through the transition. And thus, they could get rid of poverty. So they can be combined with each other. Second, according to different classification criteria, scholars also have different opinions on the classification of ecological migration studies. Therefore, different classification system is also formed. For example, Peihai Feng (2004) argued that ecological migration could be divided into six different types. While, Bao Zhiming (2006) classified ecological migration from the perspective of immigration status and mode of production. Third, the analysis of the necessity of ecological migration. This study is representative by Fang Bing, Liu Xuemin, Chen Jing, East cloth, Hou Dongmin and other scholars. Some scholars, such as Cui Xianyong and Haiying (2004), put forward some specific suggestions on the specific implementation process of ecological resettlement activities from a micro perspective. Such as, the State should provide preferential policies to ecological resettlement and establish ecological resettlement fund to protect ecological immigrants in the process of recovery process. Moreover, 
there should be the corresponding benefits for ecological migrants in the micro-credit. Furthermore, the necessary ecological compensation mechanism should be establishment. Fourth, the study of the relevant policies in ecological migration, and the problems during immigration. In the aspect of ecological immigration policy, Huang Junfang and Wang Ling (2004) put forward the basic principles of ecological immigration from the macroscopic point of view. However, from a micro perspective, Cui Xianyong and Haiying (2004) put forward some specific recommendations for the specific implementation of ecological migration activities. Fifth, from the motivation of migrant relocation (due to the ecological and environmental factors), the purpose of the relocation (living in harsh ecological conditions, residents living to better living conditions), immigration (initiated by the government A planned, unidirectional, long-term immigrant) to analyze the characteristics of ecological immigration. Finally, the study focuses on the concrete measures in the process of ecological resettlement. Shi Guoqing et al. (2009) argued that measures to avoid conflicts of ecological migration included the establishment of the mechanism of ecological resettlement compensation and the implementation of the degree of participation of immigrants. While, Mei Danfen (2006) focused on the analysis of the ecological migration system under the guidance of the plight of the operation from three dimensions, such as the government, immigration, benefit from the uncertainty.

\section{The Status Quo of Ecological Migration in Ethnic Areas}

Wu Ligeng (2003) suggested that ethnic issues in ecological migration should be obtained more attention. And he believes that people should focus more on environmental protection and ecological improvement. Xiaoying et al. (2005) proposed that tourism and green ecological industry should be combined to seize the opportunity of national ecological engineering construction and promote the construction of urbanization in ethnic areas by means of ecological resettlement. Qing Xiangyang (2006) agreed that the choice of urbanization should be the main way to protect the ecological migration in the near area. The construction of a scientific nature in reserve level, and the formation of resource protection zones protect the interests of the community under government and ethnic residents. Based on the study of an ecological resettlement village in Inner Mongolia, Xun Lili (2006), attempted to discuss the specific process of the policy for ecological migration which marked by the green symbol and discussed the local communities of national and ethnic minority in the context of modernization interaction. Li Ting (2008) took Xichang County of Ningxia as an example to analyze the adaptation of ecological migrants in Hui area. Yan Qiuyuan (2010) took the ecological resettlement community as the research object, and took the Etuoke flag of Inner Mongolia as the actual investigation point to discuss the formation and development of the community of ecological immigrants. From the perspective of economics, Gadan CaiRang used the references of Inner Mongolia, Xinjiang, Ningxia and other ethnic areas, analysed the ecological migration of Sanjiangyuan human capital, urbanization and self-development on the basis of ecological migration experience,. Zhou Peng (2013) in his doctoral thesis, studied the issue of ecological migration, and explored the development model for the western ecological migration from the perspective of sustainable development.

In summary, the academic research has been related to the relevant areas. However, the related content still need to be explored further. First, the study on the changes of ecological migration patterns and the influencing factors in ethnic areas is relatively weak. Secondly, there are few studies on the relationship between ecological migration and ecological environment in the study of ecological migration. 


\section{Changes of Ecological Resettlement Mode of X County (Yi) in Liangshan Prefecture}

\section{The Basic Situation of Yuexi County and the Picture of Removal}

X County belongs Sichuan Province, Liangshan Yi Autonomous Prefecture, which located in the southwest of Sichuan Province, North of Liangshan. From 2001, X County began to implement the relocation of ecological migration projects. They applied the policies of the relocation of poverty alleviation and returning farmland to forest, grazing, grassland, natural forest protection and other ecological construction projects to reduce poverty, and thus improve the ecological environment, and promote economic, social, ecological coordinated development. Before the relocation, this group is mainly distributed in the county's "half of the mountain" (the locals generally at an altitude of 1800 to 2000 meters or so mountainous area called "second half") and high altitude areas. While in the low mountain valley, the poor were relatively few. The distribution of the main areas had the following characteristics: high altitude, poor weather conditions; frequent natural disasters; lack of serious water; relatively small land; remote location, traffic inconvenience and information occlusion, living conditions and so on.

\section{The Living Conditions and Livelihood Patterns after the Relocation}

\section{The basic situation after the relocation}

Since 2001, X County began to implement ecological immigration project. First of all, the way of moving was divided into "the overall move out" and "part of the move out". In the same migration point in the masses under the premise of voluntary, the overall relocation is preferred. The placement is divided into centralized placement and decentralized placement. For the relatively good placement of the region, centralized placement is chosen. Decentralized resettlement is preferred under the better centralized placement, such as in the township government, village committees, schools, hospitals or along roads to reduce infrastructure spending, the cost of infrastructure and relocation costs. The factors of resettlement covered transportation, drinking water, transmission, farmland and resettlement housing construction, and also include education, culture, health and other necessary living and social facilities. The improvement of the production conditions of resettlement areas, the development of special industries should also be conerned. After the implementation of the project, the resettlement relocation to the new resettlement land production, living and living conditions have been improved.

\section{The Recovery of Livelihood after the Relocation}

How to help and guide the ecological migration to carry out production, play self-motivation, increase production income, get rid of poverty, is the difficulty of ecological migration work. First of all, before the implementation of the project, the local government combined with the local geographical environment, natural conditions, according to local conditions to choose the project. Such as, use Y village to ecological cattle as a breakthrough. Each family raise a cow, and planting potatoes, buckwheat, etc. as the basic rations in the same time to carry out family farming and planting industry, and thus to accumulate of production time experience. At the same time, the government helps to guide the ecological migration to establish a reasonable source of household income. And each household are basically guaranteed a person engaged in basic agriculture, animal husbandry production and a suitable for migrant workers. Second, the State actively encourage ecological immigrants to carry out second or thrid industries. $Z$ village is closer to the county, and thus infrastructure construction requires a lot of labor. Under the guidance of the government, many immigrants are in this labor. Third, play the national superiority. Yi women in Liangshan are good 
at embroidery. Embroidery is mostly black or white as the basis, coupled with red and green and other colored flowers, embroidered on the clouds moire, Fang Sheng pattern. These rich national characteristics of the embroidery, will be unified acquisition into the market.

Moving the Yi people from the mountains into the dam area, so that the way of livelihood shows a variety of recovery characteristics. And thus the speed of its cultural changes is accelerated. Compared with the original, immigrants will take the initiative to learn new farming techniques and planting methods to strengthen the land management, regular fertilization, weeding, and insect removal. But because of the mode of production and cultural changes brought about by them, they are still in a short period of time in the confusion and adaptation period.

\section{Changes of Ecological Migrants in the Northwest of Sichuan Province}

The northwestern part of Sichuan Province is a national area which dominated by Tibetan and Qiang ethnic groups, and also the ecological resource center of Sichuan Province. There are a large number of nature reserves in the region, and also has large density, rich national culture, backward economic development and low urbanization rate. The economic development and ecological balance of the region are mutually constrained, and the population development is in harmony with the harmony between man and land. Natural disasters and resource development are mutually restricted. So that the local residents into a difficult economic development of a fragile disaster - the population of poverty in the vicious circle of population development difficulties

\section{The basic situation and the plan before movement in W County}

W County is located in western Sichuan Province, and use Tibetan, Han, and Yi as the main body; back, Miao, white, Yao, Qiang, Tujia and other twelve ethnic minority counties. Tibet, Han, $\mathrm{Yi}$ are the three main ethnic groups to account for almost one third of the population. For a long time, the various ethnic groups blend and develop together, which forms a unique folk culture, and contains both Tibetan unique style, and Yi area unique primitive and simple. The livelihood of the residents of the original mode of livelihood mainly to farming, animal husbandry, management and work-based, the choice of livelihood is dependent on land and its natural resources, which resulted in a balanced ecosystem pressure. This siuation is not conducive to the stable development of population for long-term.

\section{Life status and livelihood recovery after relocation}

\section{The basic situation after the relocation}

From 2004, under the auspices of the government, the ecological disaster area is mainly moved to next and use centralized placement method. Because of the extreme ecological environment, making the income of ecological immigrants, the people strongly urged the implementation of immigration. Finally, the government will help to relocate immigrants to the ground. So each household will have new house, kitchen, and hardened the courtyard dam, do a good job of access, water, power project. At the same time, a high-quality high-yield mulberry garden 300 acres and four mulberry 460 acres is also completed. Cultivating silkworm mulberry industry and supporting the solution of the silkworm room improved the conditions of immigration production. 


\section{The recovery of the livelihood after the relocation}

The importance of land for farmers is self-evident. Daily necessities and vegetables are mainly concentrated to plant in the households in front of the plots, and the distribution of arable land planted food crops mainly. In addition, before the relocation, animal husbandry and aquaculture as the main source of income for immigrants here. However, after the relocation, due to the surrounding land belongs to the collar near the village, there is no place to support cattle, sheep. At the same time, in the protection of the environment and health point of view, the Government does not allow sheep around. So animal husbandry for immigrants is not want to give up but had to let go.

In contrast, the newly established mulberry garden attracts the attention of a large number of immigrants. The benefits of sericulture relative to the higher, but also have to pay a lot of effort.

Interview: "We did not raise it before. This seems to be able to earn more money, so we should learn. We do not understand it before ah. But the government provided the training teachers and they are very responsible. And there are regular people to sericulture training. Although, it's hard to take care of yourself. However, I'll like it gradually."Special people come to visit. We are only responsible for raising, selling these seems to be unhappy."

The sericulture income is relatively good in the local. Thus, some migrant workers, also choose to come back to work on sericulture industry. It can be said that the government support the industry, access to a substantial benefit. So far, the village has set up two sericulture professional cooperatives.

It can be seen that when the animal husbandry gradually withdraw with the time, the aquaculture industry has a better development here. In addition to this, like many other villages, working out is also another choice to recovery the immigrant livelihood. It should be pointed out that young people are the main force of migrant workers. However, the lack of skills, poor adaptability, or seasonal issues are the main problems for migrant workers. But the villagers are not good at this way of livelihood. On the one hand, they completely lose the accumulation of experience in the past. On the other hand, there is lack of freedom for working compared with their original state of life. In the beginning, the young people might hold the mentality to see the outside. After a period of time, they will be more willing to return home to work. Time free and acceptable income are the main reason. At the same time, immigrants are high homogeneity in the local area. Therefore, it is not easy for them to produce the sense of inferiority in the outside.

Interview: "Do you like to go out to work?" "Just want to go out to see, and later I found that I cannot adapt because I know nothing. And people still laughed at you. So it is better to go home free."'There is no training here?" "For sericulture, yes. And for others, we did not have the spirit to do it, and later did not. The people live here are in low cultural level, and lack of the ability to receive things. We like the freedom. If we go out to work. We have to live under control. So we do not like it"

After the migration, the animal husbandry had to be given up because of natural conditions. But the habits of immigrants still affect their way of life. Especially for older people, the ability to learn new knowledge and accept new things is relatively poor. Therefore, they can only rely on previous experience to find a new way of development. There is still a long way to go for immigrants who have previously relied entirely on nature. 


\section{The performance of dilemma for the livelihood of ecological immigrants}

After the migration of ecological immigrants, the way of the livelihood which are closely related to the original living environment have changed. This is both an opportunity and a challenge. Especially for ethnic areas, in addition to life, with the change of life and productive patterns changed. The way to combine the local culture and the ecological environment can not only help to protect the environment, but also benefit from the environment goals. Of course, either government, immigration or society have made efforts for ecological migration projects, but at this stage, there are still many problems in the process of ecological resettlement in this area.

\section{The sustainability of "planning" from government}

From view of the livelihood of the recovery for immigrants after relocation, the government played a leading role in it that was assumed to be the "big parents". From the selection of resettlement sites, the construction of resettlement sites, the choice of livelihood restoration projects, the source of household income structure, to the encouragement of different sexes to participate in different division of labor. However, how to use their knowledge and ability to make a living, and get rid of the government's dependence as soon as possible, is an important factor the ecological migration in sustainable development.

\section{The relationship between changes in the ecological environment and livelihood choices}

From the ecological migration before and after the migration, it can be seen that the changes of ecological environment led to different livelihood.

Before the relocation to the alpine climate, it is suitable for planting buckwheat, barley and other food crops. And alpine grassland also provide a place to cattle and sheep. After the relocation of the ground, it is not suitable for the development of animal husbandry, and land fertility is not as good as before. Thus, livelihood is facing a transformation. The livelihoods of immigrants cannot be effectively played and used. When faced with livelihood dilemma, migrant workers have little income because there is no master of the corresponding skills and lack of self-management ability. Of course, after the relocation of the relevant livelihood of the purpose of selection, are also and the local environment is closely related. Therefore, changes in the ecological environment directly led to the transformation of livelihoods, thus affecting the income of immigrants.

\section{The loss of public resources}

Ecological migration or project migration always have good public resources, including rivers, grasslands, forests and so on. These resources provide a large number of living materials and living places. Migration resulted in the loss of the original public wealth, however in the same time, it has brought a lot of inconvenience as well. The economic income from the cattle, sheep, digging Cordyceps are not available at the moment.

\section{The lack of immigrant subjects}

From the proposal of The World Bank, resettlement work should consist the principle of "people-oriented" and respect for the subjectivity of immigration. The sustainability of migration and the allocation of living conditions should also be concerned. In the planning of immigration, we should consider the needs of the resettles and the areas of production, life, society, culture and resources. 
Interview : "Uncle, how is the feeling of life now?" "Better than the original in the mountains. Before that, there is a break of the grain for three or four months each year. While, now we have the remaining. Now the question is how to do? In the past few years the government supposed us to plant nuts. We did, but not in a good price." "Do you want to plant?" "We do not know what to do. And we think the government certainly will not harm us all. For the loss, we do not want to blame the government, just blame bad luck. "" That you want to do? "" I want to raise cattle and sheep, want to do a fishing farm, marketing is certainly good. $60 \%$ of the villagers want to develop breeding. People from Leshan, Emei and other places come here to buy cattle and sheep. The market is ready. We just afraid of no money, no loan, so we cannot do anything."

Interview : "The government has a lot of projects that introduced into the village, which one do you like?" "We are afraid to distinguish ourselves." The government has suggested to rise pigs, to plant species, and medicine. And now the government also suggest us to cure tobacco. It can be said that in the village, most of the family's income is basically relying on the tobacco. "" What will you do next? "''Do not know. We are just anxious. There is no problem for life in recent year. But after a few years later, when the country did not give subsidies, and we do not know what to do next. But it is impossible to starve to death. Now we can only take a step by step. "

After the relocation, following the government is the choice when they face to new life,. While, the problem is that immigrants have their own plans for their own development, which is not necessarily consistent with the government planning projects. But there still need to establish a good communication between government and immigrants about how to start, and how to choose. In the process of making plans in details, the Government should collect these views widely. And then discuss with the immigrants to determine the final implementation project through scientific arguments.

The government should change its role from the full sweep of the "parents" to "free-hand" gradually. The government should work as "backup force" to actively adjust and to encourage the immigrants to develop independently.

\section{Conclusions and Discussions}

The ecological migrants in this paper are government-oriented and voluntary. They moved from high mountain regions to the current places they're living in, and experienced different places' environments, lives, means of livelihood, and so on. First, what we can know is that with the increase of immigration projects, the accumulation of related experience, the cooperation of ecological migrants and other factors, the implementation of ecological migration projects have made big progress. However, there are still some problems, especially all kinds of predicaments that showed in the phase of livelihood reconstruction, for example, "the sustainability of schemes of government", "loss of public resources", "the absence of the main body of migration", and so on. Those problems are major obstacles of the ecological migration's sustainable development. I will offer some related advice on them.

Make it possible to choose settlements which have similar production modes with the previous ones

This way of settlement is to reduce difficulties created by production, living, cultural customs and other aspects. If ways of production and living are changed at once, the difficulty of migrants' adaptation and living will be increased, especially for those less-educated or aged migrants. And 
that isn't helpful for their later livelihood reconstruction. Therefore, to act according to circumstances and choose settlement on the basis of an enough investigation, understanding and assessment of migrants make a great difference to different ecological migrants' livelihood reconstruction.

\section{Start with the participatory development concept and impart capabilities to migrants}

Our country's previous rebuilding of livelihood modes is always related with the sole-subject governmental rescues, which are used to relieve policy migrants and mega-disaster migrants. The mode of livelihood reconstruction is sole, because the supply mode of "land exchange" is mainly applied and the help with their living abilities and the improvement of their living endowments are ignored. Therefore, the previous rebuilding should not be called a real rebuilding. And about the ways of improving their abilities, it's necessary to have the participation of themselves. Taking the participation way of bottom-up is helpful for soliciting their wills widely, having a real understanding of their needs, giving reasonable training to them, and increasing their skills and programs' success rate. Their qualities of life will be improved then.

\section{Combine ethnic cultural wisdom with the protection of environment}

Ethnic groups have, in the process of survival in thousands of years, shaped the ecological wisdom and technical system of living in harmony with the natural environment of places they're living in. Basically, the environmental issue is the issue of the relationship among human beings, culture and nature. Human beings, to seek their living and development, are familiar with their cognition of nature's temper and traits in some specific regions, and then from generation to generation, they keep the habit of getting along with nature, which, as a systematic resource, makes them coexist with nature through adjustments and trials, respect ethnic cultures and the application of local knowledge, realize the importance of all ethnic traditional knowledge, abandon ecocentrism and cultural centralism, and focus on the acculturation between local groups and natural environment.

\section{References:}

[1] Fang Bing, Peng Zhiguang: Ecological Migration: A New Idea of Poverty Alleviation and Ecological Environment Protection in Western China, Nanning, Guangxi People's Publishing House, 2002, P72.

[2] Bai Le, Si Baocairen: On the Cultural Changes of the Ecological Migration in the Three-river Fountainhead, Journal of Fudan University(philosophy and social edition), 2007(3):134-140.

[3] Li Jin: The Patterns of Ecological Migration Settlement in Hengduan Mountains of Sichuan Province, Guizhou Ethnic Studies, 2007(1): 68-79.

[4] Hou Lan: Study on the Livelihood Reconstruction of Poverty Population in Frequent Natural Disasters - A Case Study of Qichuan Town, Sichuan province, Southwestern University of Finance and Economics, Master Thesis, 2014.

[5] Ma Xiaoqin: Local Knowledge and Regional Ecological Environment Protection, Qinghai Social Sciences,2006(2):128-134.

[6] Cao Hongmin: A Study on the Model of Rural Development and Poverty Alleviation in China, Doctoral Dissertation, China Agricultural University, 2003(6). 
[7] Zhou Peng: A Study on the Sustainable Development Problem of Ecological Migration in Western China, Doctoral Dissertation, Minzu University of China,2013(5).

[8] Dagula, Huggiletu, Shi Zhu: An Analysis of Impacts of Ecological Immigration Policy [J]. Ecological Economy, 2010(10)75-84.

[9] Wang Fang, Wang Yiqian: On the Ecological Migration and Sustainable Development of Upper Yangtze river [J]. Population and Economy, 2003(2)36-47.

[10] Li Yaosong, Xu Fen, Li Xianing: A Study on the Summer Ecological Migration's Sustainable Development [J]. Social Sciences in Ningxia, 2012(1). 